\title{
The use of plant-tissue composition at hemofilter the polyserositis of pigs (illness glasser)
}

\author{
O.G. Petrova ${ }^{1 *}$, A.D. Alekseev ${ }^{1}$, V.D. Moskvin ${ }^{1}$, M.I. Barashkin ${ }^{2}$, and L.I. Drozdova ${ }^{3}$ \\ ${ }^{1}$ Ural state agrarian university, Department of infectious and non-infectious pathology, 42 Karl \\ Liebknecht street, 620075 Yekaterinburg, Russia \\ ${ }^{2}$ Ural state agrarian university, Department of surgery, obstetrics and Microbiology, 42 Karl Liebknecht \\ street, 620075 Yekaterinburg, Russia \\ ${ }^{3}$ Ural state agrarian university, Department of morphology and expertise, 42 Karl Liebknecht street, \\ 620075 Yekaterinburg, Russia
}

\begin{abstract}
The purpose of the research in the article is to study a specific infectious disease - hemophilous polyserositis of pigs, its spread in the territory of the Ural region. Epizootological analysis of Piglet morbidity was shown, laboratory studies were conducted, and recommendations for the treatment and prevention of this disease were made. Evaluation of the specific effectiveness of the plant - tissue immunomodulator "Vidoral" in the treatment of hemophilous polyserositis in pigs and increasing the protective activity of vaccines. The features of the development of the epizootic process in hemophilous polyserositis of pigs in the studied agricultural enterprises of two regions of the Ural region are characterized. The role and place of porcine hemophilous polyserositis among respiratory diseases of infectious etiology in the formation of the nosological profile of infectious pathology is determined. The drug Vidoral on a plant and tissue basis was theoretically justified and studied, and the effectiveness of its use in animals with hemophilous polyserositis in pigs was determined.
\end{abstract}

\section{Introduction}

One of the most difficult problems of modern pig breeding is respiratory diseases, which are mostly factorial. In recent years, swine lung diseases of infectious pathology occupy a leading position, which brings economic losses in pig farming. Economic losses are mainly associated with morbidity $(90 \%)$, death $(60 \%)$, and forced slaughter $(90 \%)[15,20,23]$. Causes of respiratory diseases infectious diseases of pigs are associated with pathogenic, conditionally pathogenic microorganisms called factor diseases. Factor infections of animals cause significant economic losses, which are of some importance in the fight against them. $[3,8,10,13]$.

One of such diseases is gemofilnaya polyserositis of pigs (illness Glasser). Pathogens of hemophilosis in animals are located in the mucous membranes of the respiratory tract, and

\footnotetext{
* Corresponding author: super.kafedra2013@yandex.ru
} 
show their pathogenicity when the immunity of animals decreases under the influence of these stress factors $[2,9,12,14]$.

In General, the causative agent of hemophilous polyserositis can be detected in clinically healthy pigs up to $70 \%$. Economic damage from these diseases consists of reduced productivity, lengthening of fattening periods, increased feed consumption, reduced breeding qualities, treatment costs, losses from forced slaughter, culling of affected organs and death of pigs $[5,11,16,19]$.

\section{Research materials and methods}

We used clinical, pathoanatomic and laboratory research methods, using guidelines for each research method. For the epizootic situation with hemophilous polyserositis in pigs, we studied veterinary statistical reports from 2015 to 2019 - 4 years of retrospection (1VET, 1VET A), annual reports of veterinary laboratories, including the Federal state budgetary institution ARRIAH (all-Russian Research Institute for Animal protection, Vladimir).

When studying the epizootiology of hemofilter of polyserositis of pigs were analyzed:

$>$ Data, production of epidemiological experiments and observations;

$>$ Materials of the state veterinary reporting;

$>$ Spread of infectious diseases of pigs in the studied territories;

$>$ A total of 12 samples of biomaterial were studied in the laboratory during the work period. The experiments involved 40 taken piglets.

Bacteriological diagnostics was performed on meat-peptone agar (MPA), meat-peptone broth (MPB), using dense nutrient media (Endo, Levin, Ploskirev), Selenite broth (Salmonella accumulation medium), bismuth-sulfite agar (ICA), Olkenitsky medium. The selected cultures were studied by microscopy of smears stained according to gram and Romanovsky-Giemsa.

Biochemical, hematological and pathoanatomical studies were performed according to current methods currently used in veterinary laboratories. The agglutination reaction (RA) was used for serological examination.

Studied the effectiveness of plant - tissue immunomodulator "Vigoral"in infectious diseases of animals in accordance with the patent (patent number GB 2625022 14.07.2015 G. FSBEI Usau).[1].

Digital data processing was performed using Microsoft Word and Excel application programs, average values (M), average error (m) on a Pentium PC with an Intel processor.

\section{Results and discussion}

During epizootological monitoring in the period from 2015 to 2019 , 15 infectious diseases of pigs of various etiologies were registered in pig farms in the Sverdlovsk and Chelyabinsk regions. This list included: staphylococcosis (S. aureus (pyogenes), S. saprophyticus and the most common S. hyicus), streptococcosis (more than 20 different species from the genus Streptococcus), porcine reproductive and respiratory syndrome (RNA-containing virus from the genus Arterivirus of the family Arteriviridae), dysentery (T. hyodysenteriae), chlamydia (Chl. suis, CHL. abortus, CHL. pecorum, CHL. psittaci), porcine circovirus infection (DNA-containing virus from the genus circovirus from the family circoviridae), colibacteriosis (pathogenic serotypes of $E$. coli), Piglet hemophilous polyserositis $(H$. Parasuis), Leptospirosis (L. rotopa, L. tarassovi, L. canicola), pasteurellosis $(P$. multocida), Pseudomonas aeruginosa, porcine erysipelas (Egusipelothrix insidiosa), salmonellosis (S. choleraesuis, S. enteritidis, S. typhimurium, S. hyphisuis), mycoplasmosis 
(M. hyopneumoniae), parvovirus disease (DNA-containing a virus from the genus parvovirus of the family parvoviridae), rotavirus infection (RNA-containing virus from the genus rotavirus of the family reoviridae). According to the results of monitoring, among all diseases of pigs, it was found that bacterial diseases accounted for $87.5 \%$, and viral diseases accounted for $12.5 \%$.

Circovirus infection of pigs (CVS-2) in sows in agricultural enterprises of two regions of the Ural region is associated with a violation of the grouping of adult livestock, mainly sows with their crowded content $[17,18,21]$. It was found that 426 farms $(49.6 \%)$ were involved in the epizootic process, 97196 sick animals $(61.7 \%)$ were identified.

Among the diseases that occurred in pigs, pasteurellosis can be singled out separately, since this disease is dangerous from the point of view of epizootology. Every year it is registered with different intensity in farms [4,6,7,22,24].

Between 2015 and 2019, outbreaks of pasteurellosis and hemophilous polyserositis in piglets were reported in farms that raise and sell pigs. In total, diseases were detected in 9 different farms.

According to the results of epizootological monitoring, one of the main reasons for the occurrence and development of these diseases was non-compliance with the rules of veterinary and sanitary regime by farm employees, as well as violation of generally accepted zoohygienic rules. The main clinical signs were found in animals aged 86-111 days, and the death rate of animals was $11 \%$. On the territory of the studied commodity farms, outbreaks of another equally dangerous pig disease, salmonellosis, were registered annually. Over the past decade, the incidence of animal diseases has decreased significantly, but from the point of view of the etiology of this disease, salmonellosis causes great damage to the entire pig industry.

Clinical symptoms of this pathology were registered in animals aged 55-70 days. Salmonellosis occurred against the background of complete vaccination of animals with the occurrence of gastroenteritis during weaning of piglets from sows. In this case, the course of the disease was subacute and chronic, and $13.72 \%$ of pigs were affected.

As a result of the analysis of data from regional veterinary laboratories, using the method of enzyme immunoassay, it was revealed that in the biomaterial of the studied animals, circovirus infection was detected in Association with other diseases, such as: vector-borne gastroenteritis, Piglet bronchopneumonia and parvovirus enteritis. The increase in the number of sick animals with circovirosis is associated with the widespread introduction of the latest industrial technologies in the pig industry (20.2\%).

In the complex of respiratory diseases of pigs, an important clinical sign is a violation of the functions of the respiratory system in piglets at various stages of animal rearing, both at the stage of rearing and at the stage of fattening, which is characteristic of hemophilous polyserositis. This symptom complex is characterized by: lagging of animals in growth and development in comparison with clinically healthy animals, apathy, fever, refusal of food and water, cachexia.

Pathogens of hemophilosis constantly live on the mucous membranes of the respiratory tract, and show their pathogenicity with a decrease in animal immunity. The causative agent of hemophilous polyserositis is detected by bacteriological studies up to $70 \%$ in clinically healthy pigs.

On the territory of the Sverdlovsk and Chelyabinsk regions, this disease is sporadic, but, nevertheless, over the past decade it has been registered and occupies $21 \%$ of other infectious diseases of pigs in the conditions of a pig breeding enterprise. The disease is characterized by acute and subacute course. The acute course of the disease is characterized by an increase in temperature to $40.5-41.5^{\circ} \mathrm{C}$. The main clinical signs in piglets are depression, cough, diarrhea, vomiting, and impaired coordination of movement. The animal assumed the "sitting 
dog"pose(figure 1). Pinpoint hemorrhages were observed in the area of the ears and breast. The death of animals occurred mainly 36 hours after the onset of the disease. Some piglets showed signs of arthritis with hock joint damage (figure 1).

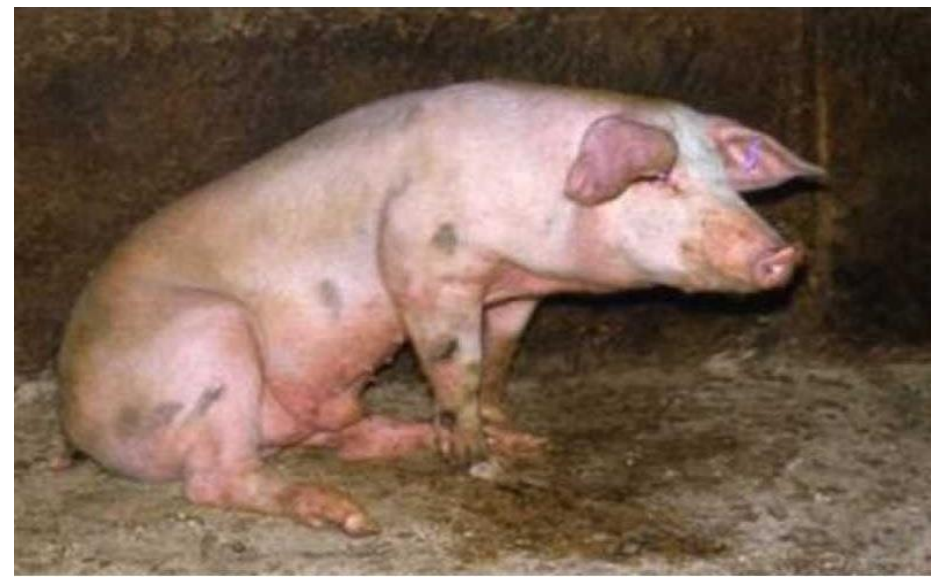

Fig. 1. Clinical signs of acute flow hemophilic polyserositis.

In dead piglets in the acute stage of hemophilous polyserositis, the accumulation of fibrinous fluid in the area of the heart SAC was noted in the range of 0.5-1 liter. In the chronic course, there were deposits of fibrin films, more often on the heart, pleura. The intestines (loops) were connected by fibrinous films. The cardiac SAC was fused with the heart, and hock injuries were observed (figure 2,3,4).

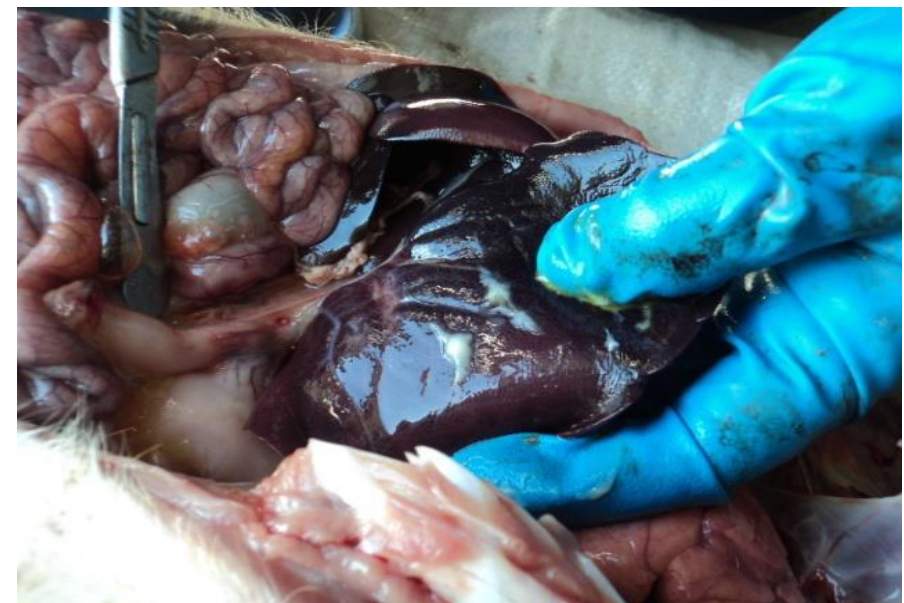

Fig. 2. Pathoanatomic changes in the liver in hemophilic polyserositis. 


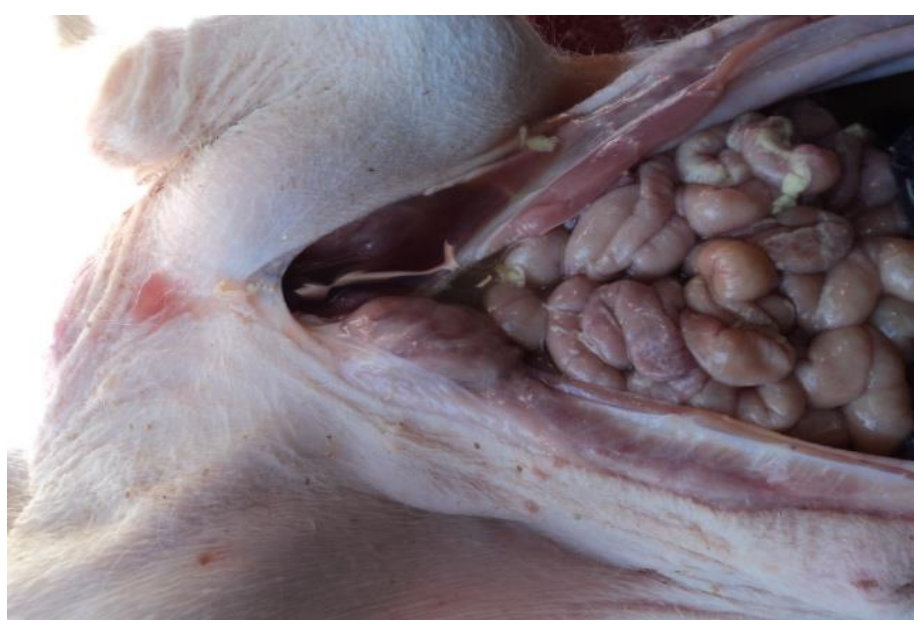

Fig. 3. Changes in the intestines of a fallen animal.

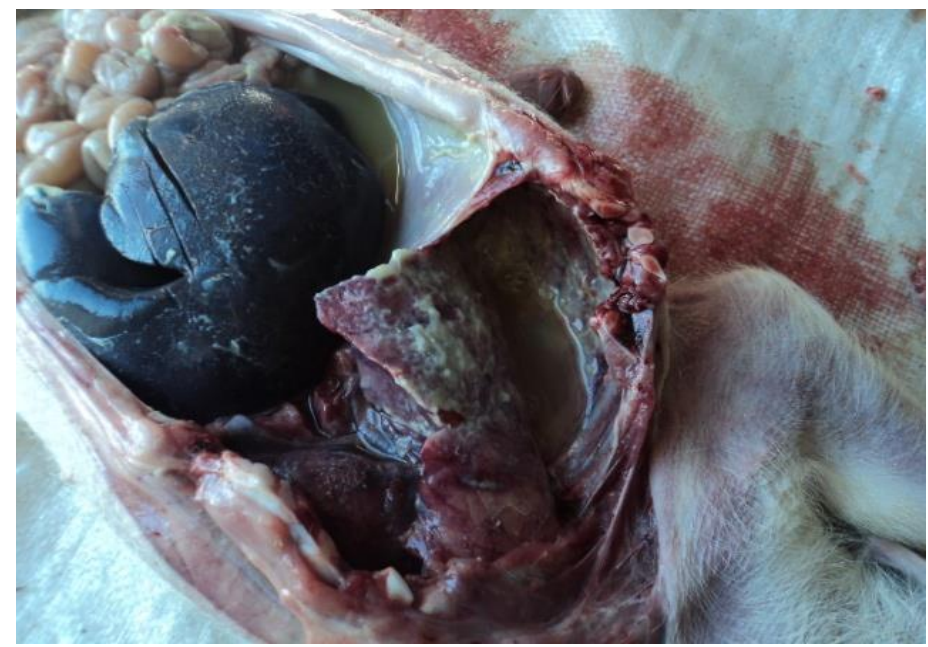

Fig. 4. Application of fibrin to the abdominal organ. 


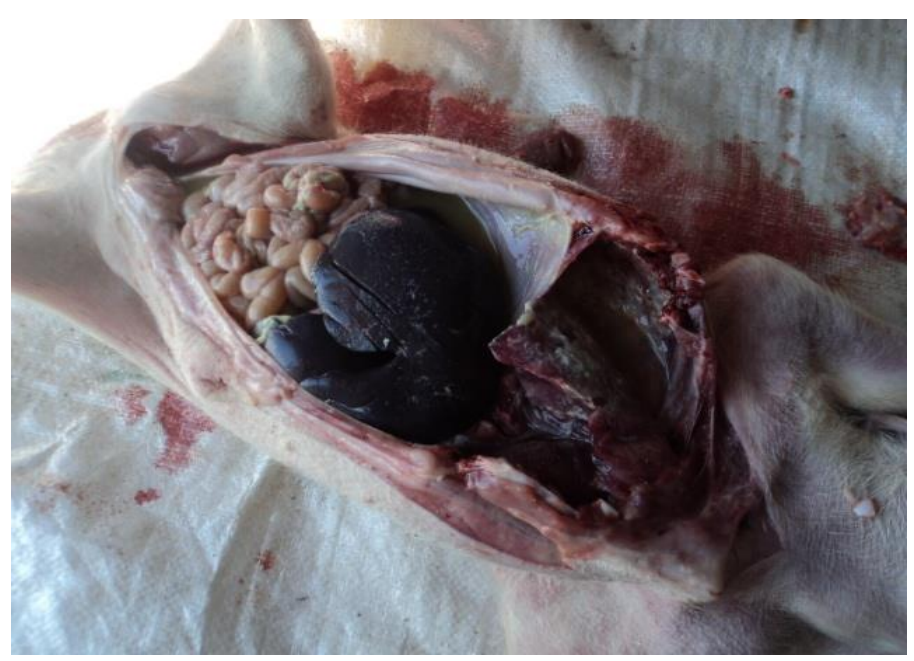

Fig. 5. Pathological changes of the internal organs of pigs with signs hemofilter the polyserositis.

Laboratory methods of research-agglutination reaction revealed antibodies to the causative agent of hemophilous polyserositis, molecular genetic isolated from the lungs and lymph nodes of dead piglets.

Based on the data obtained, it can be concluded that the main pathologies of the respiratory system, and in particular the lungs, include circovirus infection in pigs, pasteurellosis, hemophilous polyserositis in piglets, as well as salmonellosis.

We have estimated the influence of tissue immunomodulator "Vigoral" on the protective effect of the vaccine against pigs hemofilter of polyserositis. As a clinical trial, work was done to study the effect of this drug on the quality of vaccination of weaned piglets in farms in two regions.

Injections with the drug "Vidoral" were performed for five days before double immunization of animals against swine hemophilic polyserositis with inactivated vaccine against swine hemophilic polyserositis (Glesser's disease) Engelbach ${ }^{\circledR} \mathrm{HP}-1$ (vetmedica of Boehringer Ingelheim GmbH, Germany).

Clinical observation of all animals was conducted for 30 days, taking into account the titers of antibodies in the blood serum of piglets vaccinated against hemophilous polyserositis after 14 and 28 days. The experiments involved 40 weaning piglets. At the beginning of the experiment (before the first vaccination), 14 and 28 days after the second immunization, blood was taken from animals for testing in the agglutination reaction (figure 6).

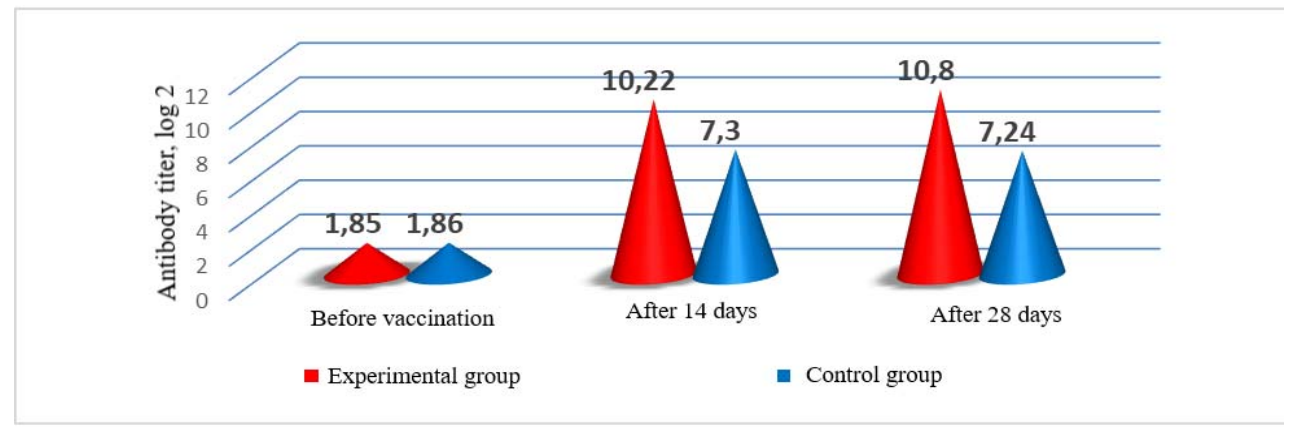

Fig. 6. The titers of specific antibodies in the serum of pigs vaccinated against gemofilnoj of polyserositis $(\mathrm{n}=40)$ 
The results shown in figure 6 show that before the introduction of the vaccine in piglets of all groups, antibodies to specific antigens were detected in titers $1.85-1,86 \log 2$, which is partly due to the presence of colostral antibodies and the phenomenon of immunizing subinfection. 14 days after vaccination against hemophilous polyserositis, an increase in the antibody titer of $5.5 \%$ was detected in the experimental group. A study of blood sera conducted after 28 days showed an increase in antibody titers in the experimental group of $5.9 \%$, in the control group, the titers of antibodies to specific antigens increased by $3.8 \%$ compared to the experimental group of animals.

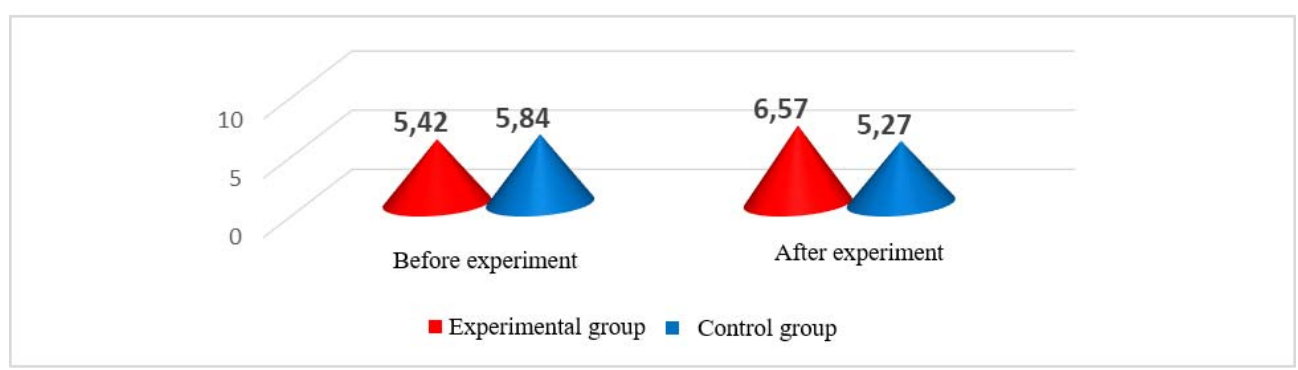

Fig. 7. Effect of the drug "Vidoral" on the level of red blood cells, $x 10^{12} / 1(\mathrm{n}=40)$

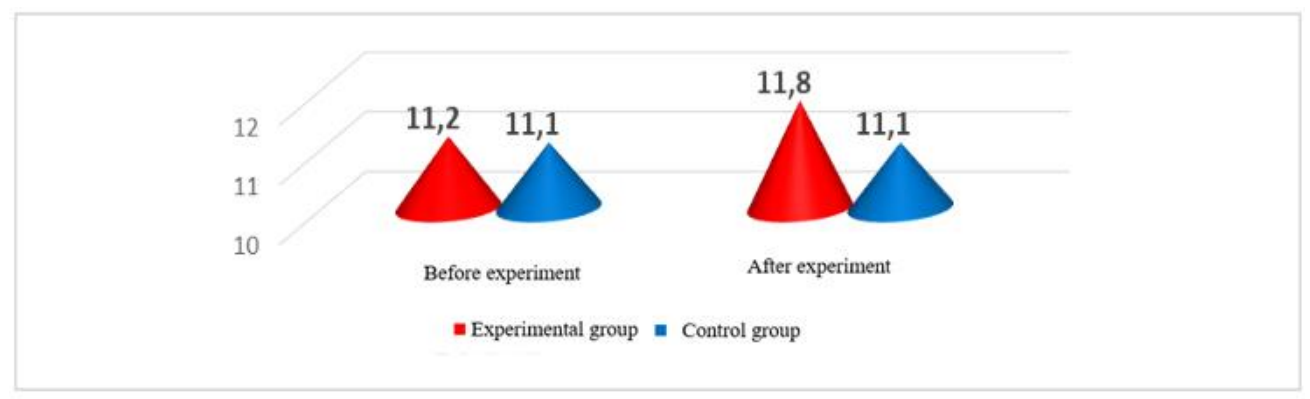

Fig. 8. Effect of the drug "Vidoral" on the level of white blood cells, $x 10^{9} / 1(n=40)$

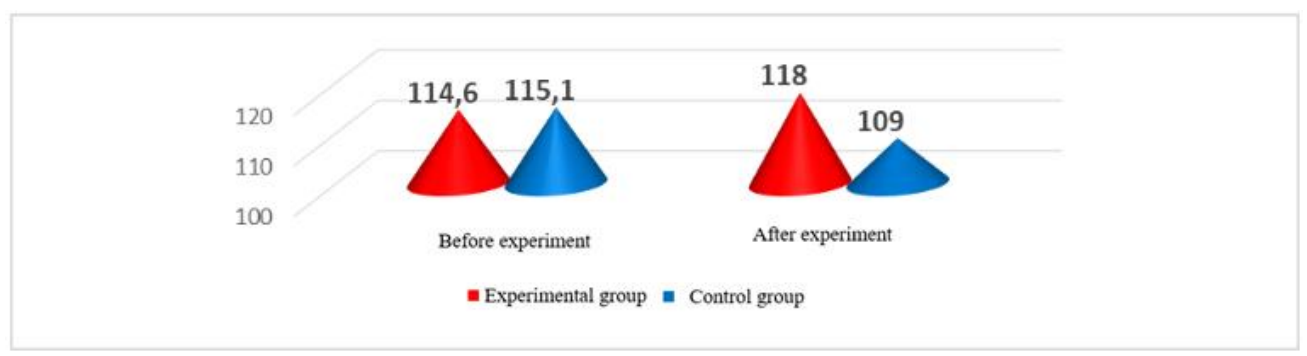

Fig. 9. The influence of the drug "Vidoral" to the level of a hemoglobin, $g / 1(n=40)$

When studying blood samples from animals that were injected with the plant-tissue immunemodulator "Vidoral", it was found that the level of red blood cells, white blood cells and hemoglobin in the experimental group No. 1 increased by $3-6,7 \%, 4-6 \%, 1-4 \%$. accordingly. 


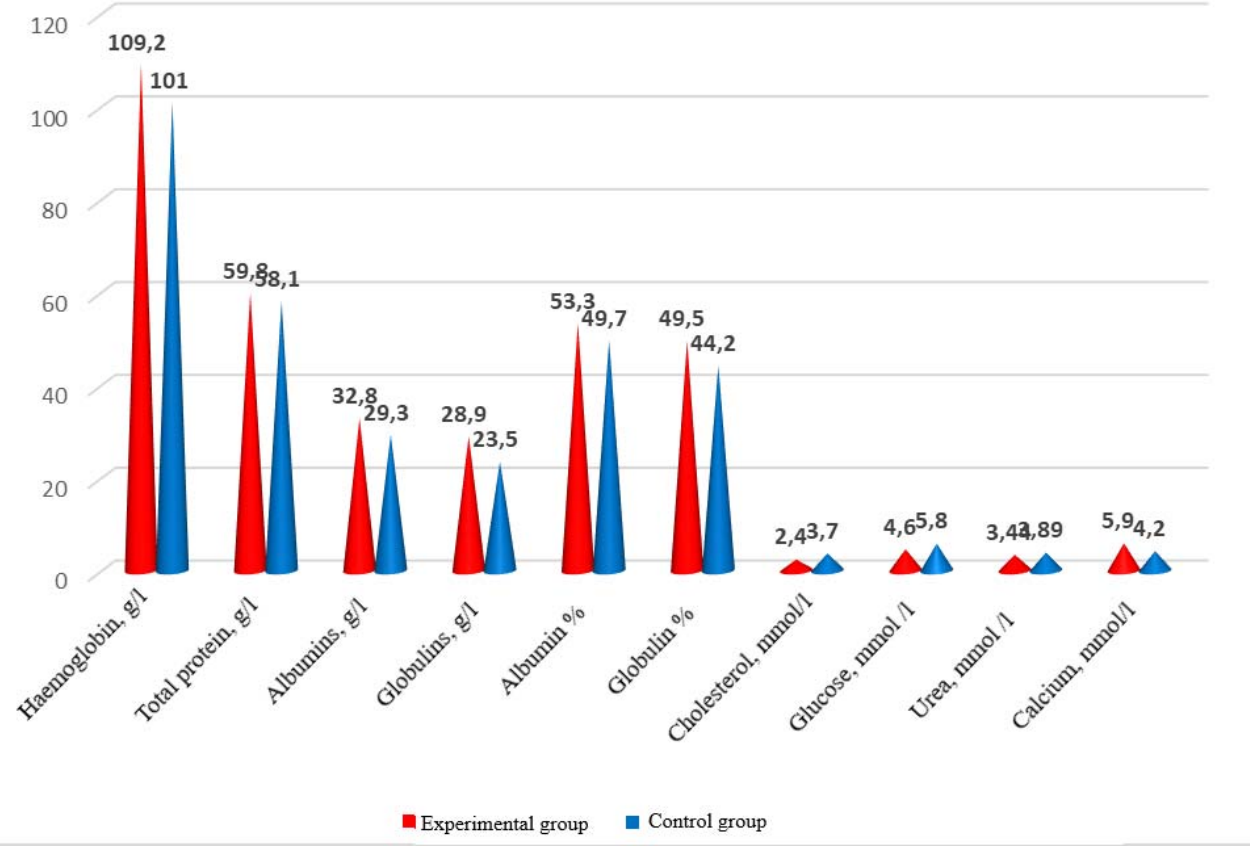

Fig. 10. Biochemical blood parameters of weaned piglets when using the drug "Vidoral" (average data, $\mathrm{n}=40$ )

According to biochemical indicators, it was found that 30 days after the start of the experiment, there was a significant increase in hemoglobin, total protein, albumins, globulins, glucose, and calcium in the experimental group by an average of 1.7 times.

When determining the safety of piglets in the control group was $70 \%$, in the experimental $100 \%$, respectively. The average daily growth of piglets was observed in the experimental group.

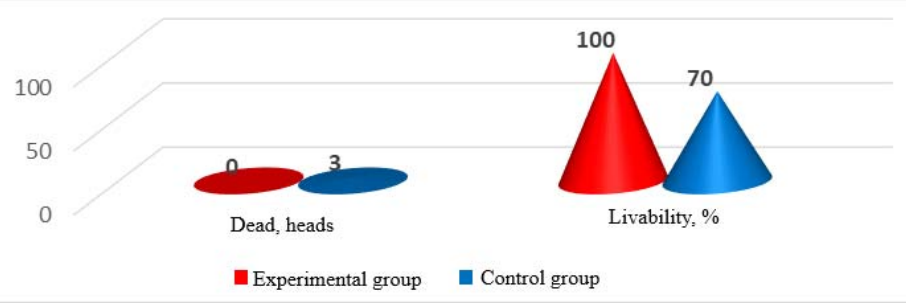

Fig. 11. Safety of piglets in the use of drugs "Vidoral". 


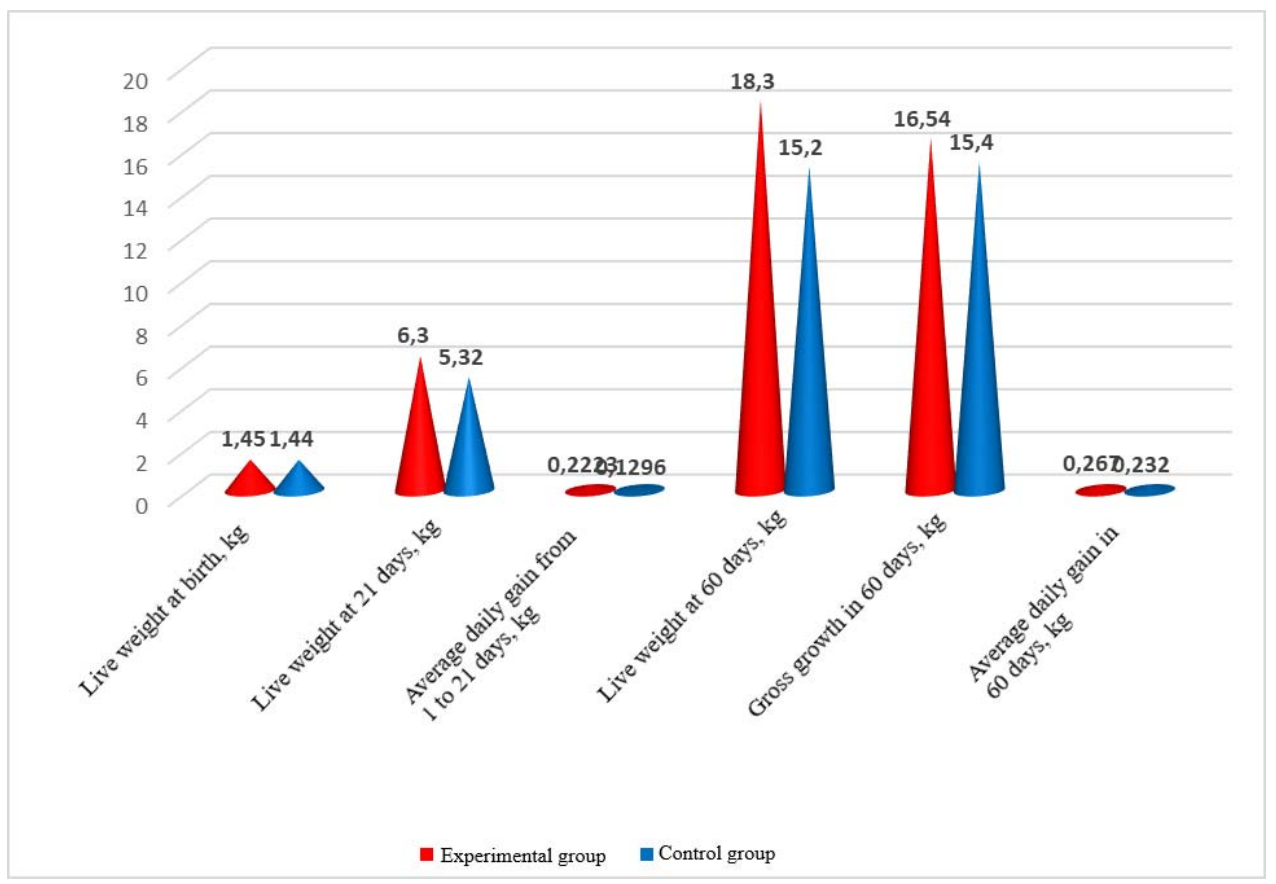

Fig. 12. Dynamics of changes of alive weight using the drug "Vidoral".

Indeed, it can be argued that the use of the plant-tissue immunomodulator "Vidoral" on vaccinated piglets can maintain the highest peak of the antibody titer against the pathogen of hemophilous polyserositis, increase live weight gain and safety of piglets.

\section{Conclusions}

Hemophilous polyserositis is one of the urgent problems in many pig farms. As a result of laboratory studies (polymerase chain reaction method) of pathological material (lungs and lymph nodes) in piglets of 35 days of age, the pathogen $H$. parasuis was detected. Also, 7 samples of blood serum from pigs on the same farm were selected for serological examination, which were sent to the laboratory of the Federal state budgetary institution "ARRIAH". The study was conducted by the agglutination reaction (RA) for the presence of antibodies to Haemophilus parasuis. In conclusion, it was said that of the 7 samples examined, all were positive, that is, they were found to contain antibodies to this pathogen. After that, it was decided to include vaccination against swine hemophilous polyserositis in the plan of anti-epizootic measures. The Ingelvak ${ }^{\circledR} \mathrm{HP}-1$ vaccine was used (Beringer Ingelheim Vetmedika GmbH, Germany). According to the results of our study, it was found that the use of the tissue immunomodulator "Vidoral" has a positive effect on the immune system of piglets, since serological methods revealed a high titer of antibodies to the pathogen after the use of the immunomodulator. Also, after using the drug, some biochemical and hematological parameters changed, which favorably affects the body and increases its resistance to the development of this disease. When conducting a study of the drug "Vidoral" on piglets, the safety of piglets in the control and experimental groups was $70 \%$ and $100 \%$, respectively. The largest average daily growth of piglets is observed in the experimental group of piglets. The economic effect on 1 head of the resulting increase in live weight in the experimental group was 9.2 rubles per 1 ruble of costs. 


\section{References}

1. A.D. Alekseev, O.G. Petrova. Application of plant-tissue composition for the prevention of acute respiratory viral infections of cattle, Collection of materials of the VI International scientific and practical conference, Perm Institute of the Federal penitentiary service, Perm, 6-9 (2019)

2. I. Volkov, Pig breeding, 5, 31 (2004)

3. V.V. Gusev, S.I. Prikhodko, S.I. Pavlov, M.G. Teymurazov. Veterinary medicine, 2, 7 8 (2004)

4. E.V. Guseva, T.A. Satina, Veterinary medicine, 81, 116-121 (2003)

5. S.I. Dzhupina, Veterinary medicine, 3, 6-9 (2001)

6. A. Isaeva, A. Krivonogova, Veterinary medicine of farm animals, 7, 43-47 (2017)

7. N.A. Kapachinskikh, Yu.G. Krysenko, E.I. Troshin, Morphological composition of blood in piglets with hemophilous polyserositis in piglets, In the collection: Agrarian science: search, problems, solutions. Materials of the International scientific and practical conference dedicated to the 90th anniversary of The birth of the honored scientist of the Russian Federation, doctor of agricultural Sciences, Professor V. M. Kulikov, 224-228 (2015)

8. O.V. Kostenko, Agrarian science of the Euro-North-East, 20(3), 290-297 (2019)

9. Y.G. Krysenko, N.I. Kapachinskih, Pathomorphological changes of the respiratory tract in hemofilter the polyserositis of pigs, In the collection: Innovative technologies for the implementation of the program of scientific and technical development of agriculture. Proceedings of the International scientific and practical conference: in 3 volumes. Izhevsk state agricultural Academy, 268-271 (2018)

10. Yu.G. Krysenko, A.V. Menshikov, Measures for the prevention of actinobacillus pleuropneumonia in pigs, In the collection: Innovative technologies for the implementation of the program of scientific and technical development of agriculture. Proceedings of the International scientific and practical conference: in 3 volumes. Izhevsk state agricultural Academy, 277-282 (2018)

11. I.V. Lobanov, V.I. Pleshakova, N.A. Lesheva, Bulletin of Omsk state agrarian University, 2(38), 146-151 (2020)

12. I.V. Lobanov, V.I. Pleshakova, N.A. Lesheva, Bulletin of the Buryat state agricultural Academy named after V. R. Filippov, 1(58), 53-59 (2020)

13. V.V. Makarov, V.N. Afonin, A.G. Shakhov, A.I. Anufriev, Veterinary pathology, 3(14), $13-22(2005)$

14. A.V. Molokova, O.G. Petrova, I.A. Rubinsky, N.A. Kolberg, Agri-Food policy of Russia, 6, 69-71 (2012)

15. B.G. Orlyankin, T.I. Aliper, E.A. Nepoklonov, Veterinary medicine, 11, Z-6 (2005)

16. O.G. Petrova, I.M. Donnik, A.G. Isaeva, Yu.G. Krysenko, Agrarian Bulletin of the Urals, 1 (119), 31-35 (2014)

17. O.G. Petrova, I.M. Donnik, A.G. Isaeva, Yu.G. Krysenko, Agrarian Bulletin of the Urals, 2 (120), 36-39 (2014)

18. V.I. Pleshakova, T.G. Siplevich, Ensuring veterinary well-being at a pig-Breeding enterprise, In the collection: prospects for the production of new-generation food products. Materials of the all-Russian scientific and practical conference with 
international participation dedicated to the memory of Professor Georgy saprygin, 120 122 (2017)

19. O.V. Pruntova, V.S. Rusaleev, V.M. Gnevashev, O.I. Ruchnova, A.V. Potekhin, F.A. Shiryaev, Bacteriological diagnostics of hemophilous polyserositis in pigs, Federal state budgetary institution "Federal center for animal health protection"1, 229-234 (Vladimir, 2005)

20. V.S. Rusaleev, O.V. Pruntova, D.A. Lozovoy, Actinobacillosis pleuropneumonia of pigs, Federal state budgetary institution "Federal center for animal health protection", 13 (Vladimir, 2018)

21. T.G. Siplevich, V.I. Pleshakova, V.S. Vlasenko, N.A. Lesheva, Feed additives on the state of natural resistance and immunological indicators of piglets, In the collection: Modern problems and scientific support of innovative development of pig breeding. XXIII international scientific and practical conference, 231-237 (2016)

22. A. Shakhov, M. Sosnina, M. Lebedev, Pig breeding, 5, 26 - 28 (2008)

23. A.G. Shakhov, L.Yu. Sashnina, M.I. Lebedev, A.I. Nikulin, Veterinary practice, 3 (42), 52-55 (2008)

24. L.I. Chekasina, Agrarian Bulletin of the Urals. 9, 89-90 (2008) 